\title{
Practical Considerations for High Impedance Restricted Earth Fault Relay Settings
}

\author{
P. V. Subramanian · L. Ajitha
}

Received: 7 May 2013/ Accepted: 28 April 2014/Published online: 12 July 2014

(C) The Institution of Engineers (India) 2014

\begin{abstract}
A strategy for practical specifications of restricted earth fault (REF) relay settings of power transformers based on the high impedance principle has been described in this work. The conventional REF relay settings rely on the principle that the REF current transformers on the phase and neutral sides of the main power transformer are having identical parameters and hence the normal settings for REF relays depend on this assumption. It is found that in the conventional literature for REF relay settings normally available there is no attempt has been made to assume unequal CT parameters on the phase and neutral ends of the power transformers. In this work, an attempt has been made to formulate generalized equations for REF relay spill currents based on unequal CT parameters and to derive practical REF relay settings therefrom.
\end{abstract}

Keywords Restricted earth fault relay settings .

Power transformer . High impedance principle .

Current transformers

$\begin{array}{ll}\text { Abbreviations } & \\ \mathrm{I}_{\mathrm{sec}} & \begin{array}{l}\text { Secondary current of CT (assumed same } \\ \text { on both sides for simplicity in the case of } \\ \text { equal CT ratios at both ends) } \\ \text { Excitation amps (total) of the phase } \\ \text { side CTs } \\ \mathrm{Ie}_{1}\end{array} \\ \mathrm{Xm}_{1} & \begin{array}{l}\text { Excitation impedance of all phase CTs } \\ \text { considered in parallel }\end{array} \\ \mathrm{RCT}_{1} & \begin{array}{l}\text { Secondary resistance of CTs at phase } \\ \text { end } \\ \mathrm{I}_{1}{ }^{\prime}\end{array} \\ & \text { Secondary current through } \mathrm{RCT}_{1}\end{array}$

P. V. Subramanian $(\varangle) \cdot$ L. Ajitha

Tebodin \& Partner LLC, Muscat, Oman

e-mail: nsubrama@gmail.com
$\mathrm{RL}_{1} \quad$ Total lead resistance from switchgear CTs upto relay
RL Relay location
$\mathrm{R} \quad$ Stabilizing resistor value
$\mathrm{Ie}_{2}, \mathrm{RCT}_{2}, \mathrm{Xm}_{2}, \quad$ Similar parameters between the relay $\mathrm{RL}_{2}, \mathrm{I}_{2}{ }^{\prime}$ etc. and transformer REF CT end
$\left(\mathrm{I}_{1}{ }^{\prime}-\mathrm{I}_{2}{ }^{\prime}\right) \quad$ Relay current

\section{Introduction}

The practical problems in conventional relay settings for the REF relay settings connected with the power transformers stem from some of the following reasons especially for the high impedance based protections:

- Somewhat unequal measured ratios of the CTs actually delivered at site for the phase and neutral ends of the main power transformer. This has happened many a time due to the manufactures being different and it becomes practically difficult to ensure proper coordination in the manufacturing process of these CTs.

- Unequal saturation voltages and magnetizing currents of the different end CTs due to the same reasons as indicated in 1 st item.

Due to such reasons as enumerated above, the consultants have faced situations when there is a strong request from the clients to see whether there is a way of realistic settings for high impedance based REF relays such that the settings are justified to overcome the practical deficiencies in the CT parameters. These measures were required to save the commissioning time when the deficiencies have been noticed after the equipment is actually delivered at site. It has been difficult in such cases to adopt the conventional procedure for REF relay settings by assuming 
identical CTs at the phase and neutral ends without compromise in performance.

In the classic application examples of high impedance REF protection [1-9] the CT parameters at the phase and neutral ends are assumed identical and there is no attempt to differentiate the lead impedances to the relay at the phase and neutral ends when these might matter with unequal CT parameters in the settings. An attempt is therefore made in this work to derive generalized equations for the residual current flowing into the series circuit consisting of the relay coil and the high impedance for the through fault conditions assuming unequal CT parameters for the phase and neutral ends. It has also been indicated about the formulation of the generalized equations and how the generalized equations can be applied in practice to derive the realistic REF settings in cases of unequal current transformer parameters and lead length impedances at the phase and neutral sides of the relay location.

\section{Formulation of the Generalised Equations for the Spill Current into the REF Relay Circuit}

The generalized equations for the spill current into the REF relay circuit is derived as indicated in Fig. 1. For purposes of fault current evaluation, the normal steady state currents are ignored.

Solution of the Above Network for Circulating Currents and Relay Operating Current

In the above equivalent circuit $\mathrm{I}_{1}{ }^{\prime}$ and $\mathrm{I}_{2}{ }^{\prime}$ are the circulating currents in the two loops through $\mathrm{RCT}_{1}, \mathrm{RL}_{1}, \mathrm{R}, \mathrm{Xm}_{1}$ and $\mathrm{RL}_{2}, \mathrm{RCT}_{2}, \mathrm{Xm}_{2}, \mathrm{R}$ respectively. Therefore the current loop equations for $\mathrm{I}_{1}{ }^{\prime}$ and $\mathrm{I}_{2}{ }^{\prime}$ can be written as the following:

$\mathrm{I}_{1}^{\prime}\left(\mathrm{RCT}_{1}+\mathrm{RL}_{1}\right)+\left(\mathrm{I}_{1}^{\prime}-\mathrm{I}_{2}^{\prime}\right) \mathrm{R}+\left(-\mathrm{Ie}_{1} \cdot \mathrm{jXm_{1 }}\right)=0$

with the understanding that $\mathrm{Ie}_{1}=\left(\mathrm{I}_{\mathrm{sec}}-\mathrm{I}_{1}{ }^{\prime}\right)$

$\mathrm{I}_{2}^{\prime}\left(\mathrm{RCT}_{2}+\mathrm{RL}_{2}\right)-\mathrm{Ie}_{2} \cdot \mathrm{jxm}_{2}+\left(\mathrm{I}_{2}^{\prime}-\mathrm{I}_{1}^{\prime}\right) \mathrm{R}=0$

with the understanding that $\mathrm{Ie}_{2}=\left(\mathrm{I}_{\mathrm{sec}}-\mathrm{I}_{2}{ }^{\prime}\right)$

(where $\mathrm{I}_{\mathrm{sec}}$ is the CT secondary earth fault current, which is taken as the same on both phase and neutral sides in this case)
After solution of the simultaneous Eqs. (1) and (2) we get the following relations:

$$
\begin{aligned}
\mathrm{I}_{1}^{\prime} & =\mathrm{I}_{\mathrm{sec}} \cdot\left(-\mathrm{Xm}_{1} \cdot \mathrm{Xm}_{2}+\mathrm{j}\left(\mathrm{Xm}_{1}\left(\mathrm{RCT}_{2}+\mathrm{RL}_{2}\right)\right.\right. \\
& \left.+\mathrm{R}\left(\mathrm{Xm}_{1}+\mathrm{Xm}_{2}\right)\right) /\left(\left(\mathrm{RCT}_{1}+\mathrm{RL}_{1}+\mathrm{R}\right)\right. \\
& \left(\mathrm{RCT}_{2}+\mathrm{RL}_{2}+\mathrm{R}\right)-\mathrm{Xm}_{1} \cdot \mathrm{Xm}_{2} \\
& -\mathrm{R}^{2}+\mathrm{j}\left(\left(\mathrm{RCT}_{1}+\mathrm{RL}_{1}+\mathrm{R}\right) \cdot \mathrm{Xm}_{2}\right. \\
& \left.\left.+\left(\mathrm{RCT}_{2}+\mathrm{RL}_{2}+\mathrm{R}\right) \cdot \mathrm{Xm}_{1}\right)\right) \\
\mathrm{I}_{2}^{\prime} & =\mathrm{I}_{\mathrm{sec}} \cdot(-\mathrm{Xm} 1 \cdot \mathrm{Xm} 2+\mathrm{j}(\mathrm{Xm} 2(\mathrm{RCT} 1+\mathrm{RL} 1) \\
& +\mathrm{R}(\mathrm{Xm} 1+\mathrm{Xm} 2)) /((\mathrm{RCT} 1+\mathrm{RL} 1+\mathrm{R}) \\
& (\mathrm{RCT} 2+\mathrm{RL} 2+\mathrm{R})-\mathrm{Xm} 1 \cdot \mathrm{Xm} 2-\mathrm{R}^{2} \\
& +\mathrm{j}((\mathrm{RCT} 1+\mathrm{RL} 1+\mathrm{R}) \cdot \mathrm{Xm} 2 \\
& +(\mathrm{RCT} 2+\mathrm{RL} 2+\mathrm{R}) \cdot \mathrm{Xm} 1))\left(\mathrm{I}_{1}^{\prime}-\mathrm{I}_{2}^{\prime}\right) \\
& =\mathrm{j} \cdot \mathrm{Isec} \cdot(\mathrm{Xm} 1(\mathrm{RC} 2+\mathrm{RL} 2) \\
& -\mathrm{Xm} 2(\mathrm{RCT} 1+\mathrm{RL} 1)) /((\mathrm{RCT} 1+\mathrm{RL} 1+\mathrm{R}) \\
& (\mathrm{RCT} 2+\mathrm{RL} 2+\mathrm{R})-\mathrm{Xm} 1 \cdot \mathrm{Xm} 2-\mathrm{R}^{2}+\mathrm{j}((\mathrm{RCT} 1 \\
& +\mathrm{RL} 1+\mathrm{R}) \cdot \mathrm{Xm} 2+(\mathrm{RCT} 2+\mathrm{RL} 2+\mathrm{R}) \cdot \mathrm{Xm} 1))
\end{aligned}
$$

\section{Derivation of the Generalised Settings Using the Above Equations and Recommended Procedure for REF Settings}

In the conventional case with identical $\mathrm{CT}$ parameters, the assumptions made are that $\mathrm{RCT} 1=\mathrm{RCT} 2=\mathrm{RCT}$ and $\mathrm{Xm} 1=1 / 3 \quad \mathrm{Xm} 2$ during normal operating conditions. However, for external fault stability, in order to get the maximum stability voltage the phase end CTs may first be assumed saturated and $\mathrm{Xm} 2$ impedance assumed as high (i.e., $\mathrm{Xm} 1=0$ and $\mathrm{Xm} 2=\infty$ ). With the further assumption that the relay is located close to the phase end $\mathrm{CTs}(\mathrm{i} . \mathrm{e} ., \mathrm{RL} 1=0)$ the expression for $\left(\mathrm{I} 1^{\prime}-\mathrm{I} 2^{\prime}\right)$ reduces to the following:

$$
\left(\mathrm{I}^{\prime}-\mathrm{I} 2^{\prime}\right)=\mathrm{Isec} \cdot \mathrm{RCT} /(\mathrm{RCT}+\mathrm{R})
$$

The corresponding stability voltage is therefore equal to:

$$
\left(\mathrm{I}^{\prime}-\mathrm{I} 2^{\prime}\right) \cdot \mathrm{R}=\mathrm{Isec} \cdot \mathrm{RCT} \cdot \mathrm{R} /(\mathrm{RCT}+\mathrm{R})
$$

The open circuit voltage therefore to be considered in the above case (of relay location close to the phase end $\mathrm{CTs}$ ) before introducing the series resistor is simply equal to Isec.RCT which agrees with the conventional norms.
Fig. 1 REF relay circuit with respect to spill current

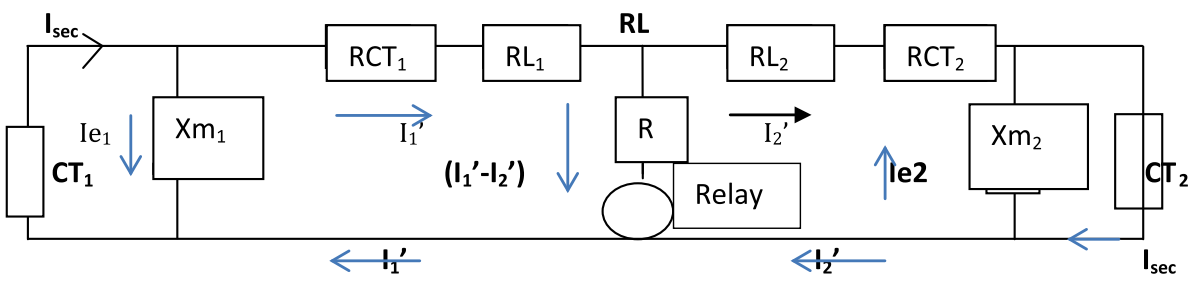


Under the same assumptions the neutral end CT secondary voltage developed reduces to:

Isec $\cdot($ RCT + RL2 $) \quad($ Where RL2 $=2 \mathrm{RL})$

Again in the conventional case with the assumption of neutral CT getting saturated and further with the assumption of RL1 = 0 (Relay located close to the phase CTs) and $\mathrm{RL} 2=2 \mathrm{RL}$ the stability voltage reduces to the following:

$\mathrm{Vs}=\mathrm{Isec} \cdot(\mathrm{RCT}+2 \mathrm{RL}) \cdot \mathrm{R} /(\mathrm{RCT}+2 \mathrm{RL}+\mathrm{R})$

In the above case again the open circuit stability voltage at phase end (before introducing $\mathrm{R}$ ) therefore reduces to :

Isec $\cdot(\mathrm{RCT}+2 \mathrm{RL})$

The above also becomes the CT secondary voltage development requirement for the case considered.

[The above relations (3) and (4) express the conventional secondary voltage development requirements reported normally in the literature for phase or neutral end CTs with identical parameters. It may be noted that these values are equal in the conventional case with identical CT parameters at the phase and neutral ends.]

However using the most generalized relationships derived in sections above, the actual CT parameters, RL1, RL2 etc. can be substituted for any practical case and the stability voltage can be computed simply as:

$\mathrm{Vs}=\left(\mathrm{I} 1^{\prime}-\mathrm{I} 2^{\prime}\right) \cdot \mathrm{R}$

In order to arrive at the correct values of CT secondary voltages, as per standard practices the CTs at the relay (panel) end and neutral end are assumed saturated in turn and the corresponding values of CT secondary voltages to be developed are considered for further minimum saturation voltage (Vk) specification.

It may be recognized that the stabilizing resistor value is common and therefore when the assumption of either end CT saturation is used each assumption will give rise to a different value of setting current for the corresponding stabilizing voltage. Therefore the final value of setting current should be corresponding to the higher value obtained. The application example indicated below would make this procedure clear.

\section{Application Example}

The following is an application example with different parameters of CTs at the phase and neutral ends actually delivered by the vendors to illustrate the principle of settings adopted in such a case:

Parameters of phase end CTs actually used:

Magnetizing impedance, combined $(\mathrm{Xm} 1)=$ 29,445 ohms
CT secondary resistance $(\mathrm{RCT} 1)=9.9 \mathrm{ohms}$

Parameters of Transformer neutral end CT actually used:

Magnetizing impedance $(\mathrm{Xm} 2)=74,100 \mathrm{ohms}$

CT secondary resistance $(\mathrm{RCT} 2)=5 \mathrm{ohms}$

Other parameters:

Total lead resistance RL1 $=0.2 \mathrm{ohms}$

Total lead resistance RL2 $=2$ ohms

Stabilizing resistor value used $(\mathrm{R})=800 \mathrm{Ohms}$

If $=42,670$ amps. CT Ratio $=3,200 / 1 \mathrm{~A}$

Isec $=42,670 / 3,200=13.33 \mathrm{~A}$

With the above parameters the following results were obtained.

Case A: (CTs at the Transformer neutral end assumed saturated)

Relay current: 0.11 amps

CT secondary volts developed at panel end: $226.76 \mathrm{~V}$

CT secondary volts developed at transformer neutral end: 0 Volts due to the saturation assumption

Actual Vk of procured CTs for the panel end: $530 \mathrm{~V}$

Case B: (CTs at the panel end assumed saturated)

Relay current: 0.165 amps

CT secondary volts developed at panel end: $0 \mathrm{~V}$ due to the saturation assumption.

CT secondary volts developed at transformer neutral end: $227 \mathrm{~V}$.

Actual Vk of procured CTs for the transformer neutral end: $400 \mathrm{~V}$

It may be seen from the above results that the actual relay currents in case A and case B vary by a wide margin and therefore the higher value of $0.165 \mathrm{~A}$ was considered for the actual relay setting.

Actual value of final setting considered for REF relay pick up with margin $=1.2 \times 0.165=0.2$ Amps.

In other examples considered (not reported here) the CT secondary voltage requirements at the phase and neutral ends were different by a wide margin.

\section{Conclusions}

In many actual cases where the CT parameters are not exactly identical at the phase and neutral ends of the power transformer it becomes necessary to adopt a different criterion for the REF relay from the conventional. As demonstrated in this article, by adopting a generalized approach using the equations derived, the relay currents could be different by a wide margin for the assumptions of CT saturations at the phase and neutral ends, with unequal CT 
parameters at these ends. The generalized approach as suggested in this article can be used to advantage in such cases where required when exact parameter values can be substituted without using any approximation.

Acknowledgments The authors are thankful to Tebodin and Partners LLC for the encouragement of performing this work.

\section{References}

1. Alsthom Network Protection and Automation Guide (Protective Relays Measurement and Control), May 2011 edn. Micom 30 series, REF Protection application guide, Issue B1, Alsthom

2. A comparison between high impedance and low impedance REF Transformer protection by Casper Labuschagne and Izak Vander
Merwe, pp. 1-9. Eskom Enterprises and Schweitzer Engg (2005-2007)

3. D. Robertson (ed.), Power System Protection Reference Manual, Reyrolle Protection, Chapter 6 (Orient Press)

4. Performance of REF Protection scheme in the presence of CT remanence, ed. by K.J.A. Jallil, A.H.A. Bakae, W.N. Wan Mahadi, Hanif_Power Energy Conference, 2008 IEEE Second International 5. Application Notes for KCGG High Impedance Protection by Alsthom T\&D Protection and Control Ltd., Publication R6142B

6. Application Guide for High Stability Circulating Current Relay, Alsthom Publication Ref R6136D

7. Application Notes for High Impedance REF Protection, Section 2.3, Micom application guide NO. P64X/EN-AP/A32

8. High impedance differential relaying. GE Power Management Document No: GE 3184

9. SIPROTEC Differential Protection Manual, 7UT612, V4.0, C53000, G1176-C148-1, Siemens 